\title{
Evaluating the Acceptability of a Massive Open Online Course for UK Medical Students
}

\author{
Ka Ying Bonnie Ng ${ }^{* 1}$, Usama Syed ${ }^{2}$, Jack Garnham ${ }^{2}$, Stephanie Smith ${ }^{3}$, Ben Green ${ }^{4}$, Mahiben Maruthappu ${ }^{2}$ \\ ${ }^{1}$ University Hospital Southampton NHS Foundation Trust \\ IImperial College London \\ 3 University of Cambridge \\ ${ }^{4}$ Leeds Teaching Hospitals NHS Trust
}

"Corresponding author: Ka Y Bonnie Ng, University Hospital Southampton NHS Foundation Trust, Tremona Road, Southampton, SO16 6YD,UK, Tel: +44 238077 7222; E-mail: bonnie.ng@doctors.org.uk

Rec date: July 11, 2016; Acc Date: September 6, 2016; Pub date: September 13, 2016

Copyright: (c) $2016 \mathrm{Ng} \mathrm{KYB}$ et al. This is an open-access article distributed under the terms of the Creative Commons Attribution License, which permits unrestricted use, distribution, and reproduction in any medium, provided the original author and source are credited.

\begin{abstract}
Introduction: Massive open online courses (MOOCs) are teaching programmes consisting of a combination of online lectures, computer based assessments and discussion forums. There are already multiple examples of how the MOOC format has been employed in medical education, but little research has been done to clarify whether the format is considered a desirable teaching modality from the student perspective. Our study explores the acceptability of the MOOC structure to a medical student audience in the United Kingdom by assessing the feedback from a trial MOOC run by the UK Medical Student's Association (UKMSA).

Methods: The UKMSA designed and delivered a MOOC covering various medical and surgical topics between February and November 2014. We provided an online feedback form that asked participants to evaluate the presenters, the content and structure of the lecture, and the overall quality of the teaching.

Results: 252 students attended the MOOC lectures. 68 feedback forms were collected, providing a response rate of $27 \%$. All students agreed that material was pitched at an appropriate level, and $99 \%$ agreed that the material was relevant to their training. Over $90 \%$ of students agreed that there was a clear introduction, that the material was well organised, that the aims and objectives were clear, and that there was a clear summary and conclusion. All students agreed that the presenters appeared well informed and enthusiastic, and over $95 \%$ agreed that the presentation was informative and delivered at an appropriate pace. 67 of 68 attendees agreed that overall the teaching session was of high quality.

Conclusions: We found that MOOCs were well accepted amongst our medical student cohort. MOOCs could be used to supplement traditional methods of learning in the undergraduate setting. They may offer an innovative, interactive and cost-effective way of addressing the learning needs of medical students.
\end{abstract}

Keywords: Massive open online courses; Medical students; Artificial intelligence

\section{Introduction}

Massive open online courses (MOOCs) are teaching programmes consisting of a combination of online lectures, computer based assessments and discussion forums, that allow an unlimited number of individuals to participate in education, often free of cost [1]. Whilst online lectures have been used as educational tools for some decades, the idea of the MOOC format as a separate entity came to prominence in 2008; the term was coined to describe open access courses such as the 'Introduction to Artificial Intelligence' lectures run by Stanford University, which managed to recruit 160000 users worldwide [2].

Since this time, the popularity of MOOCs has risen exponentially, with some providers, such as Coursera, Udacity, edX, and Google Course Builder boasting a combined subscribership in the millions [3]. As high profile academic institutions, for example Harvard and MIT (the creators of edX), and companies like Google strive to join the
MOOC clamor, it is little surprise that 2012 was labelled the 'Year of the MOOC' by the New York Times [4].

As a platform that can deliver high quality learning resources to a large audience, the MOOC clearly have potential applications in medicine. There are already multiple examples in the literature of how the MOOC format has been employed in medical education. 10,000 people from 65 countries registered for a MOOC that aimed to educate lay persons about dementia, with almost 4000 individuals completing the 9 week course [5]. In 2014, Physiopedia and the International Spinal Cord Society used a MOOC to teach physiotherapy students about spinal cord injuries [6]. Sheffield University set up a MOOC to prepare aspiring dental students for future university applications [7].

The MOOC has also found traction in more acute settings; during the Ebola crisis information about the presentation and management of the disease was disseminated to a global audience using a MOOC [8]. A study by Liyanagunawardena et al. into the total number of health and medicine specific courses on offer across the main online MOOC providers found that there were 98 available through the calendar year of 2013 [9]. 
Their successful employment at this early juncture suggests that MOOCs have the potential to play a role in the provision of medical education, whether for public health purposes to a lay audience, or in a more specialised format for undergraduate and postgraduate medical professionals. Whilst there are many studies that have investigated recruitment and retention of MOOC participants, as well as efficacy, defined by test results before and after the completion of a course, less work has been done to clarify whether the format is considered a desirable and effective teaching modality from the student perspective.

Our study explores the acceptability of the MOOC structure to a medical student audience in the United Kingdom by assessing the feedback from a trial MOOC run by the UK Medical Student's Association (UKMSA). This structured feedback provides an insight into how the online modality is received by this audience and lays the foundation for future work in the field.

\section{Methods}

The UKMSA developed and piloted a new online teaching platform. This online platform, AnyMeeting [10], was originally designed for video conferencing, but we adapted its use to allow teaching in a MOOC format. We created a UKMSA account on Any Meeting, allowing presenters to upload their PowerPoint presentations. Doctors, ranging in seniority from foundation house officer to registrar, were invited to teach on surgical or medical topics of their choice.

Once a topic was agreed upon, the doctors were asked to upload their PowerPoint presentations to the teaching platform, and these presentations were reviewed by an independent UKMSA committee member and a recently qualified UK doctor. A lecture title, learning objectives, and a time and date for the lecture were set. We invited UKMSA student members to attend these MOOC lectures through an email sent two weeks prior to the MOOC and again in the few days preceding the launch.

The UKMSA members were also invited to attend the MOOC lectures on Facebook; event pages were created and links to the Any Meeting platform were provided. Students were able to attend the MOOC lecture of their choice by logging in online, providing their name, email address, and their general location.

The lecturer and all participants were able to interact with others attending the lecture via a messaging function, allowing participants to communicate throughout the MOOC. The session was interactive; students had the opportunity to ask questions or make comments, and the lecturers had the opportunity to respond to the questions and comments throughout their presentation.

There was also a protected time for questions and answers at the end of the presentation. Once the MOOC lecture finished, all the students were directed to an online teaching feedback form, which asked them to evaluate the presenters, the content and structure of the lecture, and the overall quality of the teaching. Space was also provided for additional comments. The feedback was collated and analysed. In total, 13 free lectures were run between February and November 2014.

\section{Results}

The UKMSA designed and delivered a MOOC offering 13 free lectures on various medical and surgical topics between February and November 2014. Doctors ranging in seniority from foundation house officer to registrar delivered the lectures. In total, 252 students attended the MOOC lectures. 68 feedback forms were collected, providing a response rate of $27 \%$.

With respect to the lecture content, 100 per cent of students agreed that material was pitched at an appropriate level, and 67 of 68 students (99\%) agreed that the material was relevant to their training (Figure 1).

When asked to comment on the structure of the course, $99 \%$ of students agreed that there was a clear introduction to the subject and that the material was well organised, while 64 students (94\%) agreed that the aims and objectives were clearly stated and that there was a clear summary and conclusion.

All students agreed that the presenters appeared well informed, 66 students (97\%) agreed that the presentation was clear and informative, and 65 students (96\%) agreed that the presentation was delivered at an appropriate pace and that the presenters appeared enthusiastic. 67 of 68 attendees (99\%) agreed that overall the teaching session was of high quality, with $71 \%$ registering strong agreement and no students choosing to disagree.

In all cases at least $63 \%$ of students (43 of 68) strongly agreed with the appraisal statements and 94 per cent of students (64 of 68) agreed with any appraisal statement. There were only five disagreements recorded, three relating to pacing and two relating to structure, making up less than one per cent of all responses. Representative examples of free text comments are shown in (Table 1). 
Citation: Ka Ying Bonnie Ng, Usama Syed, Jack Garnham, Stephanie Smith, Ben Green, et al. (2016) Evaluating the Acceptability of a Massive Open Online Course for UK Medical Students. Gen Med (Los Angeles) 4: 268. doi:10.4172/2327-5146.1000268

\section{Participant Responses to Likert Style Questions}

Overall this teaching session was of high quality (68)

There was a clear summary and conclusion (68)

The material was well organised (68)

The aims and objectives were clearly stated (68)

There was a clear introduction to the subject (68)

The presentation was given at the right pace (68)

The presentation was clear and informative (68)

The presenter appeared enthusiastic (68)

The presenter appeared well informed about the subject (68)

The content was relevant to my training (68)

The content was at an appropriate level (68)

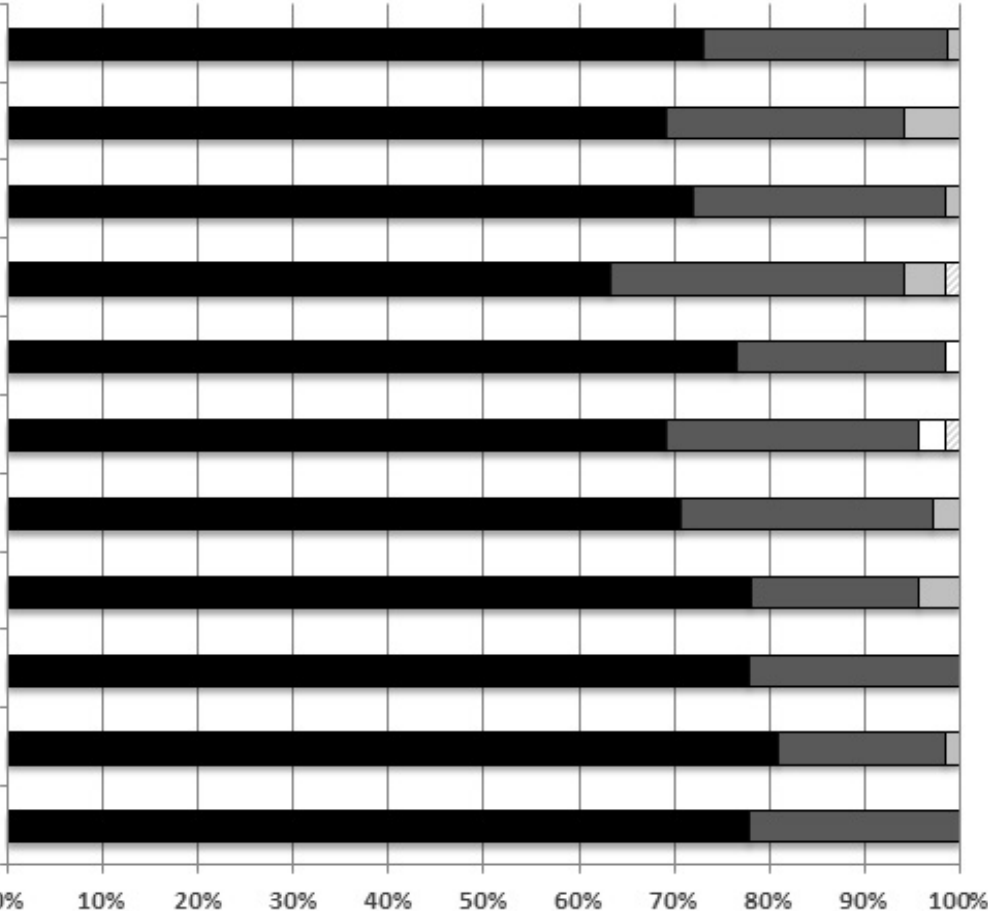

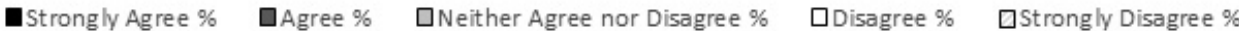

Figure 1: Participant responses to Likert-style questions. Numbers of respondents to each question are shown in parentheses after the question.

\section{Comments}

The presenter was very knowledgeable about the subject and presented at a clear, appropriate pace. She also made sure that we understood the slides throughout the presentation and gave plenty of opportunities to ask questions.

Very clearly taught. Gave a good overview from the beginning so it was easy to follow throughout. Made a difficult subject easier to learn.

Teaching through case histories was very helpful. The session was very interactive and he made sure that we understood the material as he went along.

The slides were well laid out and the content covered was very good. Everything was well explained and I think it would have been useful for all year groups.

Excellent explanation of a topic not routinely taught well.

Table 1: Representative examples of student's feedback on the MOOC lecture.

\section{Discussion}

The MOOC format provides a novel teaching platform that allows educators to disseminate knowledge to medical students on a national and international level. We aimed to explore the acceptability of our MOOC amongst medical students who were members of the UKMSA. Overall, we found that the course was well received, with feedback demonstrating that the MOOC lectures were relevant, appropriately challenging, and well structured. The presenters received similarly positive feedback on the delivery of their lectures. This suggests that MOOCs may be a welcomed teaching platform for medical students. The unique nature of MOOCs allows interaction between presenter and audience in a way that is precluded by the traditional lecture format, and provides opportunities for further discussion of complex ideas outside of the classroom. Given that MOOCs can be completed 
in conjunction with more conventional forms of learning, they may represent a method of augmenting understanding and reinforcing knowledge gained from traditional lectures and seminars, particularly when mapped to the undergraduate curriculum.

Following the success of the MOOC for aspiring dental students, an equivalent course designed to educate potential applicants about a career in medicine may be beneficial [7]. Providing prospective applicants with a realistic depiction of a career in medicine prior to application may lessen unanticipated angst or regret arising as a result of uninformed career decisions. MOOCS may also have a role in undergraduate training, providing education on specific medical topics, most likely as an optional tool to enhance learning, and allowing for uniformity in the provision of medical education across institutional, national, and international boundaries. Online courses may also provide benefit for those in less developed areas of the world; examples in the literature demonstrate that MOOCs can reach audiences that otherwise would not have had access to comparable resources, helping to minimise the effect of educational inequality $[5,11]$.

Whether MOOCs should be adopted by medical establishments and integrated into core teaching curricula, or simply exist as a supplementary learning resource, is a topic for discussion. There are those who consider MOOCs as potentially disruptive the manner in which traditional formal higher education takes place [2]. Whilst this does not appear a major issue in the foreseeable future, the idea of formal accreditation for MOOCs is not alien, with The Open University UK and several other establishments throughout the world providing similar certificates of completion. A more likely, and already witnessed, eventuality is that existing higher education establishments will embrace the modality and produce their own MOOCs, to be incorporated as a voluntary or compulsory part of their curriculum. There is already evidence for the successful adoption of MOOCs by existing universities and colleges; Coursera have over 80 University partners in their courses [2], with John Hopkins University in the United States leading the way in this regard, producing more health and medicine based MOOCs than any other University [9].

However, there remain valid concerns about the format. Whilst MOOCs can be used to disseminate high quality information to a large audience of students, they may impose controversial changes on the relationship between student and lecturer [4]. Assessment of learning is an immensely complex and controversial issue; although MOOC students can be evaluated via multiple-choice questions, in a field such as medicine specifically, assessment of 'doctor-patient' interactions and communication can only truly be achieved through physical presence. Using MOOCs to deliver medical knowledge en masse poses separate challenges; levels of a priori knowledge and individual institutional curricula can vary considerably. Our study, however, showed that this barrier is not unassailable, as our audience, consisting of medical students from various institutions in the UK, testified to the relevance of content delivered, suggesting a large degree of homogeneity when it comes to medical education. Clearly both traditional institutions and novel teaching modalities have their own strengths and weaknesses, and perhaps successful hybridisation of the two will allow us to reap maximal benefit.

At the present time there is a paucity of reliable data that depicts how well students learn from MOOCs, and also what aspects of MOOCs contribute to better or worse learning experiences [4]. Surrogate markers of engagement and learning such as the number of clicks or hours spent are often used to establish what type of content is best received. This kind of feedback is insufficient, and a commitment to the creation and analysis of MOOCs by universities could pave the way for higher quality metrics in this field in future, which in turn will allow the development of improved courses.

Moving beyond the University setting, MOOCs offer potentially exciting options for post-graduate education and continued professional development (CPD). Subhi et al. [12] assessed the potential of using MOOCs to equip qualified healthcare professionals with the skills necessary to successfully enact the roles designated by the Royal College of Physicians and Surgeons of Canada for all qualified physicians [13]. They compared all existing courses on two major MOOC platforms, edX and Coursera, categorising each depending on their potential pertinence for practitioners hoping to improve in one of the aforementioned domains. The study concluded that a commitment of 4.5 hours per week in these online resources was a realistic and effective way for MOOCs to be integrated into the postgraduate medical training pathway. In the UK, the Royal Colleges or General Medical Council could produce their own MOOCs and offer accreditation or CPD points for their successful completion. This would be a cost effective and scalable method for ensuring clinician competencies in various regards.

New and exciting technologies could also unlock further MOOC applications. A recent proof of concept study has shown that 'Virtual Patients' can be successfully incorporated into MOOCs [14], opening the door to future uses in both undergraduate and postgraduate medical education by bringing a form of 'bedside teaching' to the computer screen.

The ability of MOOCs to produce a 'global classroom' also makes them an ideal modality when it comes to the emergency dissemination of knowledge pertinent to issues of global health. A prime example of this is the Ebola MOOC that provided key information to healthcare professionals across the world at the height of the crisis in 2014 [8]. Looking forward, MOOCs could be harnessed for similar disease outbreaks, natural disasters, or simply universal healthcare concerns such as issues surrounding non-communicable diseases.

We should consider some limitations of our study. Of the 252 participants, 68 opted to provide feedback, providing a response rate of $27 \%$. Our results therefore may not be representative of the opinion of the full cohort of students. Evidence suggests that the average response rate to online evaluations of teaching is $33 \%$, and while our response rate does not differ significantly from this, it is less than optimal [15]. One could in future improve survey response rates by making feedback mandatory for attending future MOOC lectures or offering free learning material for those who complete the questionnaire post attendance. Reporting bias is another concern; students are more likely to report both positive and negative concerns, and those with moderate opinions are less likely to comment. We aimed to explore the acceptability of MOOCs to medical students in the UK, who, despite their cultural and economic diversity, represent a select minority [16]; further work should focus on whether MOOCs are an acceptable method of providing teaching to medical students from less privileged areas. In order to mitigate concerns about the quality and validity of the content, we recruited doctors who had teaching experience, allowed them to lecture on a topic with which they felt comfortable, and had at least one independent reviewer from the UKMSA committee board attending each lecture.

Despite the methodological issues, the resounding positivity towards the MOOC format in our study opens the door to serious 
Citation: Ka Ying Bonnie Ng, Usama Syed, Jack Garnham, Stephanie Smith, Ben Green, et al. (2016) Evaluating the Acceptability of a Massive Open Online Course for UK Medical Students. Gen Med (Los Angeles) 4: 268. doi:10.4172/2327-5146.1000268

Page 5 of 5

thought about how best this modality can be integrated into medical training. Our results echo the findings of others; medical education in this format may satisfy many diverse aims.

\section{Conclusion}

We found that MOOCs were well accepted amongst our medical student cohort. MOOCs may supplement traditional methods of learning in the undergraduate setting, namely lectures, tutorials and seminars. They introduce increased audience participation and interaction, and could be considered as an innovative and costeffective way of addressing the learning needs of medical students.

\section{References}

1. Hoy MB (2014) MOOCs 101: an introduction to massive open online courses. Med Ref Serv Q 33: 85-91.

2. Heller R (2014) Learning by MOOC or by crook. Med J Aust 200: 192-193.

3. Reich J (2015) Rebooting MOOC research. Science 347: 34-35.

4. Pappano L (2012) Massive open online courses are multiplying at a rapid pace. New York Times.

5. Goldberg LR, Bell E, King C, O'Mara C, McInerney F, et al. (2015) Relationship between participants' level of education and engagement in their completion of the understanding dementia massive open online course. BMC Med Educ 15: 60.

6. Harvey LA, Glinsky JV, Lowe R, Lowe T (2014) A massive open online course for teaching physiotherapy students and physiotherapists about spinal cord injuries. Spinal Cord 52: 911-918.
7. Stokes CW, Towers AC, Jinks PV, Symington A (2015) Discover Dentistry: encouraging wider participation in dentistry using a massive open online course (MOOC). Br Dent J 219: 81-85.

8. Grobusch MP, Browne JL (2015) A Massive Open Online Course (MOOC) to support the fight against Ebola. Travel Med Infect Dis 13: 263.

9. Liyanagunawardena TR, Williams SA (2014) Massive open online courses on health and medicine: review. J Med Internet Res 16: e191.

10. https://www.anymeeting.com/

11. Paton C (2014) Massive open online course for health informatics education. Healthc Inform Res 20: 81-87.

12. Subhi Y, Andresen K, Rolskov Bojsen S, Mørkeberg Nilsson P, Konge L (2014) Massive open online courses are relevant for postgraduate medical training. Dan Med J 61: A4923.

13. Royal College of Physicians and Surgeons of Canada (2014) CanMEDS: Better standards, better physicians, better care.

14. Stathakarou N, Zary N, Kononowicz AA (2014) Beyond xMOOCs in healthcare education: study of the feasibility in integrating virtual patient systems and MOOC platforms. PeerJ 2: e672.

15. Nulty D (2008) The adequacy of response rates to online and paper surveys: what can be done? Assess Eval High Educ 33: 301-314.

16. http://www.gmcuk.org/

The_state_of_medical_education_and_practice_in_the_UK_2012_0912. pdf_49843330.p. 